\title{
SEASONAL VARIATION IN CHIRONOMID EMERGENCE FROM COASTAL POOLS
}

\author{
ALEXANDER T. EGAN ${ }^{1, *}$, LEONARD C. FERRINGTON JR1, \\ TOBEN LAFRANÇOIS ${ }^{2,3}$, and MARK B. EDLUND ${ }^{2}$ \\ ${ }^{1}$ University of Minnesota, 1980 Folwell Ave., St. Paul, MN 55108, USA \\ 2 St. Croix Watershed Research Station, 16910 152nd St. N., Marine on St. Croix, MN 55047, USA \\ ${ }^{3}$ Northland College, 1411 Ellis Ave., Ashland, WI 54806, USA \\ *Corresponding author: egan0059@umn.edu
}

\begin{abstract}
Understanding the phenology of emergences can be useful in determining seasonal chironomid life cycle patterns, which are often influenced by ice cover and temperature in cold climates. Lake Superior is the largest lake in North America and with a mean surface temperature of $3.9^{\circ} \mathrm{C}$ influences regional climate. Coastal pools at Isle Royale, a wilderness archipelago in the northern part of the lake, occur in dense patches on low-gradient volcanic bedrock between the lakeshore and forest, creating variable microhabitats for Chironomidae. Four sites were sampled monthly from April to October, 2010. Surface-floating pupal exuviae were collected from a series of pools in two zones: a lower zone near the lake influenced by wave splash, and an upper zone near the forest and influenced by upland runoff. We used Jaccard's and Whittaker's diversity indexes to test community similarity across months. Temperature loggers in pools collected hourly readings for most of the study. Assemblage emergences were stable in upper pools, with significant similarity across late spring and summer months. Assemblages were seasonally variable in lower pools, with significant dissimilarity across spring, summer, and fall months. Few species in either zone were unique to spring or fall months. However, many summer species in the splash zone had a narrow emergence period occurring during calm weather following distinct increases in mean water temperature. Regardless of input of cold lake water to the lower zone, pools from both zones generally had corresponding temperature trends.
\end{abstract}

Keywords: Isle Royale, Lake Superior, rock pools, exuviae, diversity, zonation, water temperature

\section{Introduction}

Coastal habitats are influenced climatically by the thermal mass of large bodies of water. As a result, weather patterns can be distinctly moderated, with colder summers and warmer winters than inland areas. This climate is analogous to arctic or alpine conditions regarding the biological challenges and behavioral and physiological responses of aquatic insects (Danks 2007). With ectothermic body temperature and development regulated by the environment, these cold climates may affect biological activity, especially on annual cycles.

Climate warming is already having important influences on ice cover and solar energy storage in Lake Superior, the largest of the Laurentian Great Lakes (Austin and Coleman 2007; Desai et al. 2009). Subsequent repercussions are expected across biological communities, ecosystem functioning, and policy responses to impacts (Schindler 1997; Day et al. 2008; Hulsmans et al. 2008). The resulting community dynamics are likely to include novel assemblages and modified food webs (Lurgi et al. 2012). In particular, chironomid assemblages have been shown to respond to fluctuating water chemistry and temperature as a result of climate change (Brooks and Birks 2004).

We studied chironomid assemblages of coastal pools of Lake Superior, which are discrete habitats that are generally shallow, have a small surface area, and exhibit distinct chemistry and communities between horizontal shoreline zones (Egan et al. 2014). Despite variability in local context, pool systems worldwide often have similar features such as spatial clustering, dispersal challenges, desiccation potential and physical traits of both pools and organisms within them (reviewed in Brendonck et al. 2010). Seasonal variation is typical in small and temporary waters, and chironomid emergences are often strongly influenced by climate (Armitage 1995; Williams 1996). Having found significantly different assemblages between zones (Egan 2014), our current goals were to determine: 1) if assemblages within each zone have differential emergence patterns across months or seasons, and 2) if patterns of water temperature of pools, which are in turn influenced by weather, are associated with emergence patterns. These goals can help in modelling chironomid emergence responses to climate in lacustrine coastal pools in cold coastal areas.

\section{Materials and Methods}

\section{Study Site}

Isle Royale National Park, Michigan, USA, is a federally-designated wilderness in Lake Superior, with one large island $\left(544 \mathrm{~km}^{2}\right)$ surrounded by hundreds of small islands (Fig. 1). Vegetation is a transition between mixed boreal and northern hardwood forests. The eastern half of the park has volcanic bedrock with gradually sloping southern shores, creating good conditions for pool formation and retention in bedrock depressions. Four study sites were randomly selected using high-definition aerial 


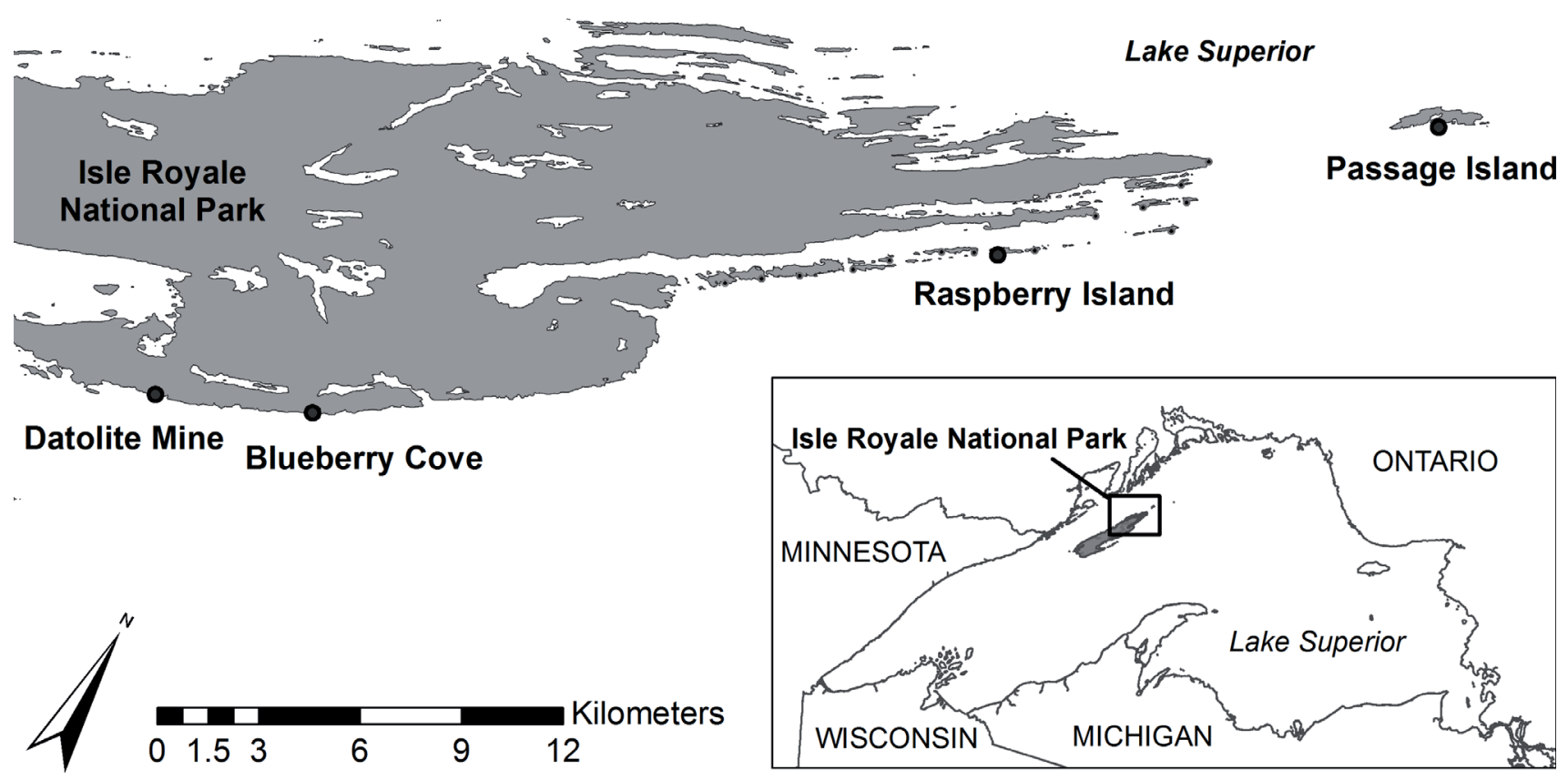

Fig. 1 Isle Royale National Park and 2010 Study sites, including regional context (inset).

photographs to determine locations with sufficient pool densities. Sites included Passage Island, Raspberry Island, Blueberry Cove, and Datolite Mine.

\section{Data Collection}

At each site, the sampling area and pools were randomly selected. From April to October, 2010, six sampling rounds occurred approximately monthly, with each round was clustered in a 3-9 day period: April 22-28, May 9-17, June 3-8, July 3-9, August 3-6 and October $2-4$. Monthly sampling was expected to be sufficient for detecting a majority of richness (Bouchard and Ferrington 2011). At each site in each round, six chironomid pupal exuviae samples were collected, with 143 total samples (one less than expected due to a dry pool on 3 June). Of the six samples, three were from upper "lichen zone" pools above the average line where wave wash was influential, and three were from lower "splash zone" pools where regular wave wash from Lake Superior was expected. The boundary between zones was typically distinct based on dense crustose lichen coverage, and for clarity of results no study pools were selected from the transition area between zones.

Collections of surface-floating pupal exuviae (also called chironomid pupal exuviae technique - CPET) have been widely used in biomonitoring and taxonomic studies (Ferrington et al. 1991; Langton 1991; Wilson and Ruse 2005). Exuviae were collected from pools using a small pan, dipped beneath the surface so water and floating material would flow in, and filtered through a $125 \mu \mathrm{m}$ sieve. During each visit, twenty minutes of total sampling occurred in each zone: five minutes of sampling occurred for each of two deep, permanent pools and ten minutes of sampling from available shallow, ephemeral pools. Due to variable hydroperiods, ephemeral pools required opportunistic sampling during each visit, but pool permanence was not considered important for seasonal analyses since assemblages were statistically similar between pool types (Egan 2014). Eight thermistors were placed in permanent pools, one at each site in each zone, to $\log$ hourly water temperatures from May 7 to September 30, 2010.

Depending on temperature, decomposer activity, and mechanical disturbance, exuviae were expected to float for 1-7 days (Kavanaugh et al. 2014). Collections were not made for 24+ hours following rainfall or moderate waves, which could sink exuviae. Exuviae collection allows for efficient and targeted sampling of waterbodies (Verneaux and Aleya 1999), as well as avoiding problems of removing larvae and potentially shifting the trajectory of the food web in small habitats. Among limitations of exuviae collections, a possible bias against species with light chitinization and thus faster decomposition would be influential to current analyses (Kavanaugh et al. 2014). Exuviae were slide mounted and identified to genus using keys in Wiederholm (1986) and Ferrington et al. (2008). Species-level identifications were accomplished using sources listed in Egan and Ferrington (2015).

\section{Analyses}

Monthly assemblages were pooled by zone (lichen or splash) due to significant zonal community differences (Egan 2014). Beta diversity testing used Jaccard's coefficient of community (JCC, eq. 1) and Whittaker's percent similarity (WPS, eq. 2 ) indices to test for pairwise differ- 
ences among monthly assemblages by zone. Both indices present results on a scale from 0 (no community similarity) to 1 (complete similarity), therefore the degree of similarity can be judged based on similarity or dissimilarity for each test statistic.

$J C C=2 A /(2 A+B+C)$

$W P S=\sum \min \left[p_{i J}\right.$ or $\left.p_{i K}\right]$, where $p_{i J}=n_{i J} / N_{J}$ and $p_{i K}=n_{i K} / N_{K}$

In JCC, $A=$ species shared in both assemblages being compared, $B=$ species present in assemblage one but not assemblage two, and $C=$ species present in assemblage two but not assemblage one. JCC is based on presence/absence of species and is sensitive to rarities with the potential to underestimate similarity (Chao et al. 2005). Significance values $(p<0.05)$ for similarity or dissimilarity in JCC were established using $N$ species in Real (1999). WPS is a summary of minimum percentages for each species shared between samples (Legendre and Legendre 2012); it incorporates abundance and can be biased toward highly abundant species. For WPS, $n_{i J}$ and $n_{i K}$ represent the number of individuals from a species from sample $J$ or sample $K ; N_{J}$ and $N_{K}$ represent the total number of individuals across all species from samples $J$ and $K$. Without a reference for WPS significance, we considered values $\leq 0.1$ to indicate ecologically important differences occurred. To limit diversity biases, both single dominant species (Orthocladius dubitatus Johannsen, 577 individuals) and all singletons (18 species) were removed from beta diversity analyses, with 51 species remaining. Removals reduced the chance either for WPS to homogenize results or for species collected only once to drive JCC comparisons across multiple samples.

Tukey-Kramer HSD tests were run in $\mathrm{JMP}^{\circledR}$ Pro 11.0.0 (2013 SAS Institute Inc.) to compare mean weekly water temperature in pools and JCC pairwise results between zones. One-way Analysis of Variance was also calculated in JMP using differences between adjacent monthly sampling rounds to compare changes in mean temperature to new species' emergences. Mean temperatures were from logger readings of pools at Passage Island in most months. October means had to be estimated using readings from the last week of September, while April and May were combined and changes estimated from ice-out (i.e., $0^{\circ} \mathrm{C}$ and no species) to May sampling.

\section{Results}

\section{Monthly Emergences}

Most exuviae were detected in April and June, while most species emerged in June and July (Fig. 2). While April had the second highest emergence per month, numbers were dominated by O. dubitatus ( $68 \%$ of spec- imens), which occurred in all other months. The only species that was abundant and typically only emerging in April was Limnophyes carolinensis Saether. Higher abundance of emergence occurred in the lichen zone, though the splash zone had greater diversity (Fig. 2). Proportional emergences by month revealed three species emerging only in April (Diamesa insignipes Kieffer, Limnophyes Sp. 1, Micropsectra nana [Meigen]), five in July (Pseudodiamesa branickii [Nowicki], Cricotopus magus Hirvenoja, Cricotopus annulator Goetghebuer, Heterotrissocladius Sp. A Saether, Orthocladius annectens Saether) and two in August (Thienemannimyia norena [Roback], Nanocladius nr. branchiocolus Saether). A larger assemblage of eight species was unique to June: Conchepelopia fasciata Beck and Beck, Potthastia gaedi (Meigen), Cricotopus sp. cylindraceus group, Cricotopus intersectus (Staeger), Paracladius quadrinosus Hirvenoja, Chironomus anthracinus Zetterstedt, Chironomus montuosus Ryser, Wulker and Scholl, and Paratanytarsus dimorphus Reiss. No species were unique to May or October (Fig. 3, Fig. 4).

Temporal patterns of community emergence were significantly different between zones (Table 1; Tukey-Kramer $q=2.048, \alpha=0.05, p=0.001)$. Lichen zone results were generally higher (on a scale of $0-1$ ), indicating more community similarity between monthly lichen zone samples. Most lichen zone results did not diverge from random chance, but JCC showed significantly similar assemblages emerging between May vs August and July vs August. Although we were not able to determine significance values for WPS, high values supported the similar July vs August lichen zone results determined by JCC. However, a low WPS result contrasted JCC by suggesting an assemblage dissimilarity between April vs June lichen pools.

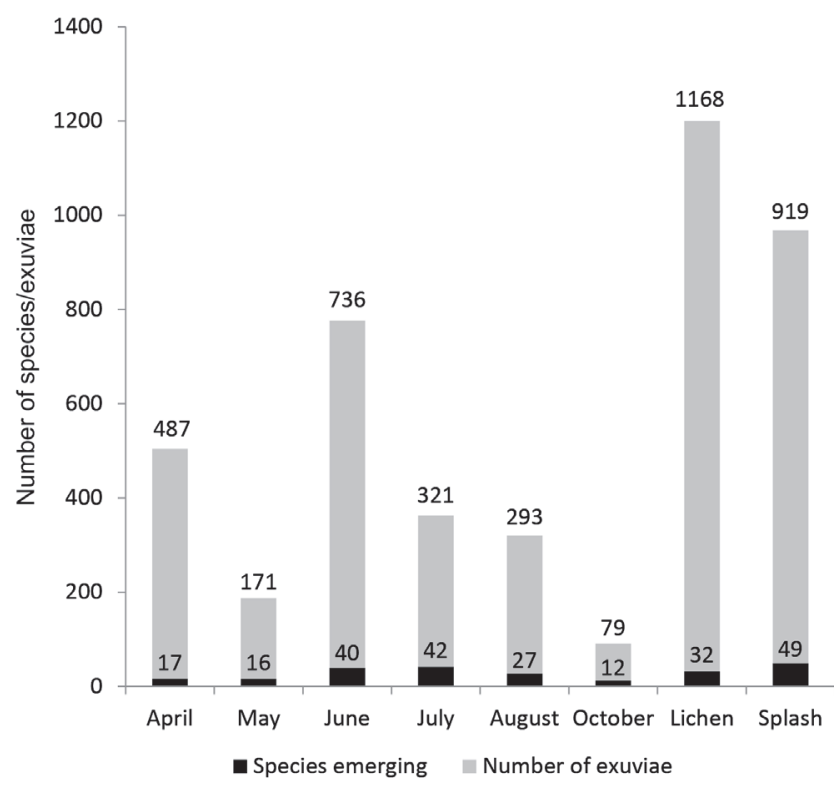

Fig. 2 Exuviae abundance (tall, light columns) and number of chironomid species (short, dark columns) emerging by season and zone from coastal rock pools, 2010. 


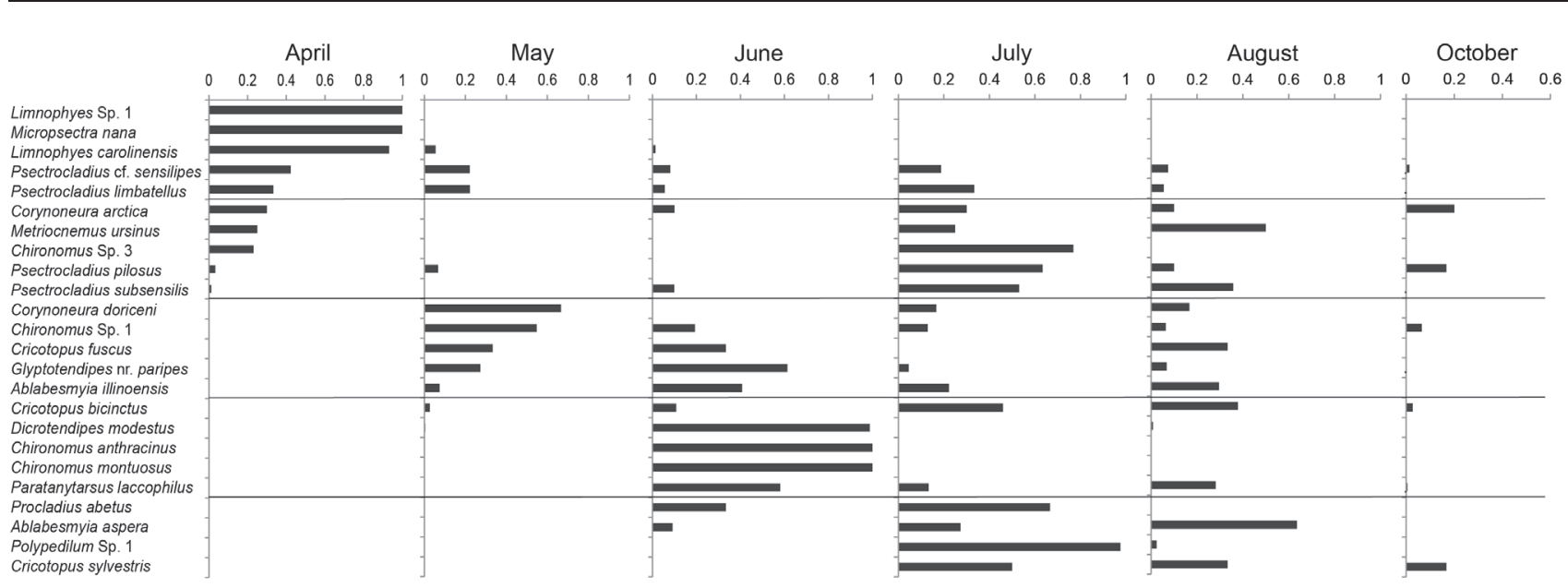

Fig. 3 Proportional abundance of monthly emergence by species used in beta diversity analyses, from lichen zone pools, Isle Royale, 2010.

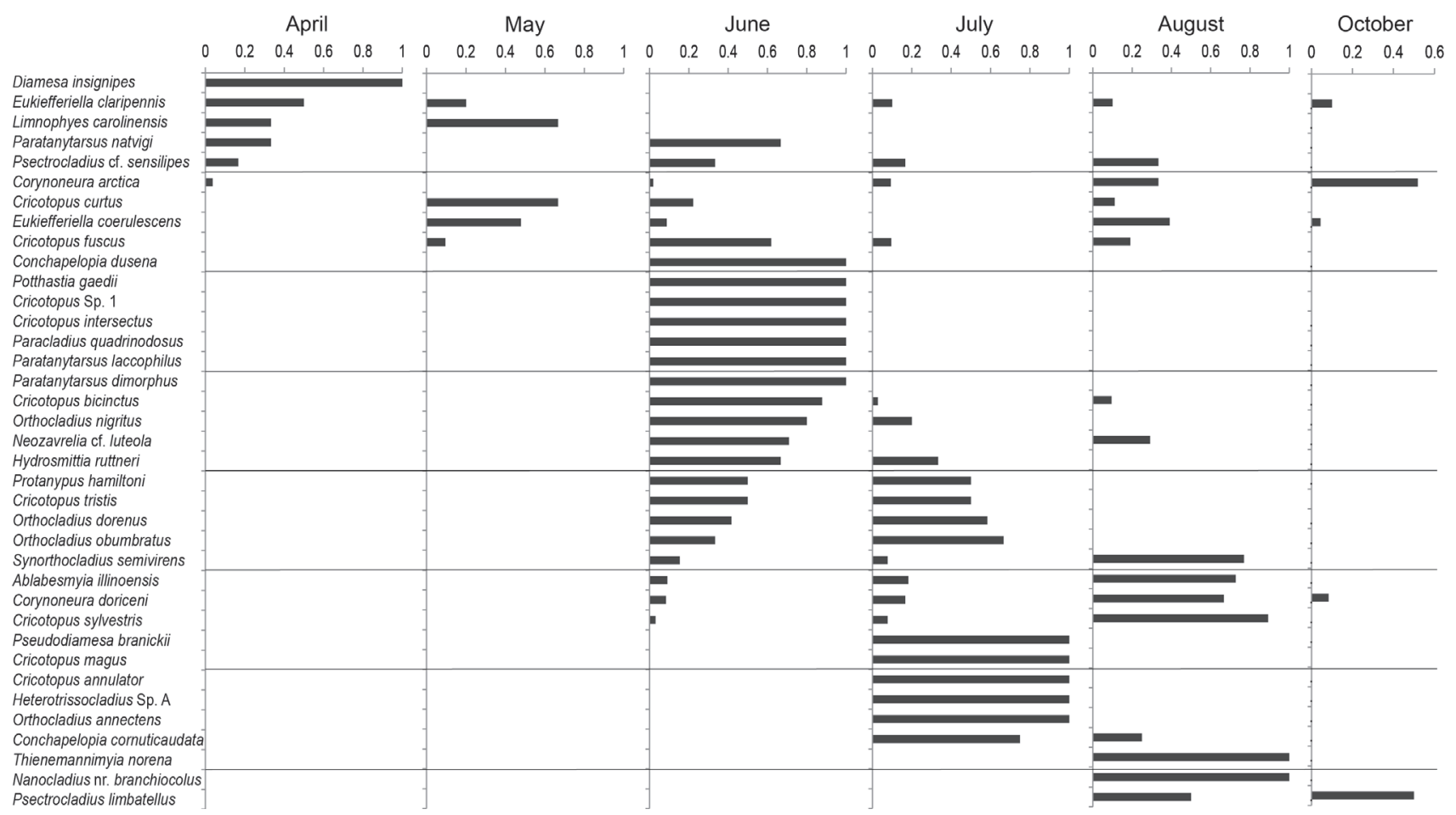

Fig. 4 Proportional abundance of monthly emergence by species used in beta diversity analyses, from splash zone pools, Isle Royale, 2010.

In contrast, assemblage similarities in splash zone pools were significantly lower than those in lichen zone pools, indicating a trend toward greater community dissimilarity between monthly splash zone samples. There were no indications of significant similarities in any month-by-month comparison of splash zone pools, either for JCC or WPS. Rather, JCC revealed April and May assemblages that were significantly dissimilar from June and July, and June and July were also significantly dissimilar from October assemblages. Low WPS results support these seasonal dissimilarities, along with suggesting that May was dissimilar from all other months except April.

\section{Temperature Patterns}

Thermistors revealed strong diurnal changes and distinct seasonal patterns in mean pool temperatures (Fig. 5). Peak temperatures in late July and early August were between $27.9-31.3{ }^{\circ} \mathrm{C}$ for the lichen zone, and $31.2-31.4{ }^{\circ} \mathrm{C}$ for the splash. Minimum temperatures in May were $4.6-7.1^{\circ} \mathrm{C}$ for lichen pools, and $2.7-3.2^{\circ} \mathrm{C}$ for splash pools. Passage and Datolite pools had distinct mean temperature changes in May and September. Passage Island was the most exposed to wave action, while Datolite Mine was the most protected, offering good contrasting sites. Two splash zone thermistors, at Blueberry and Raspberry, did not log data correctly so patterns 

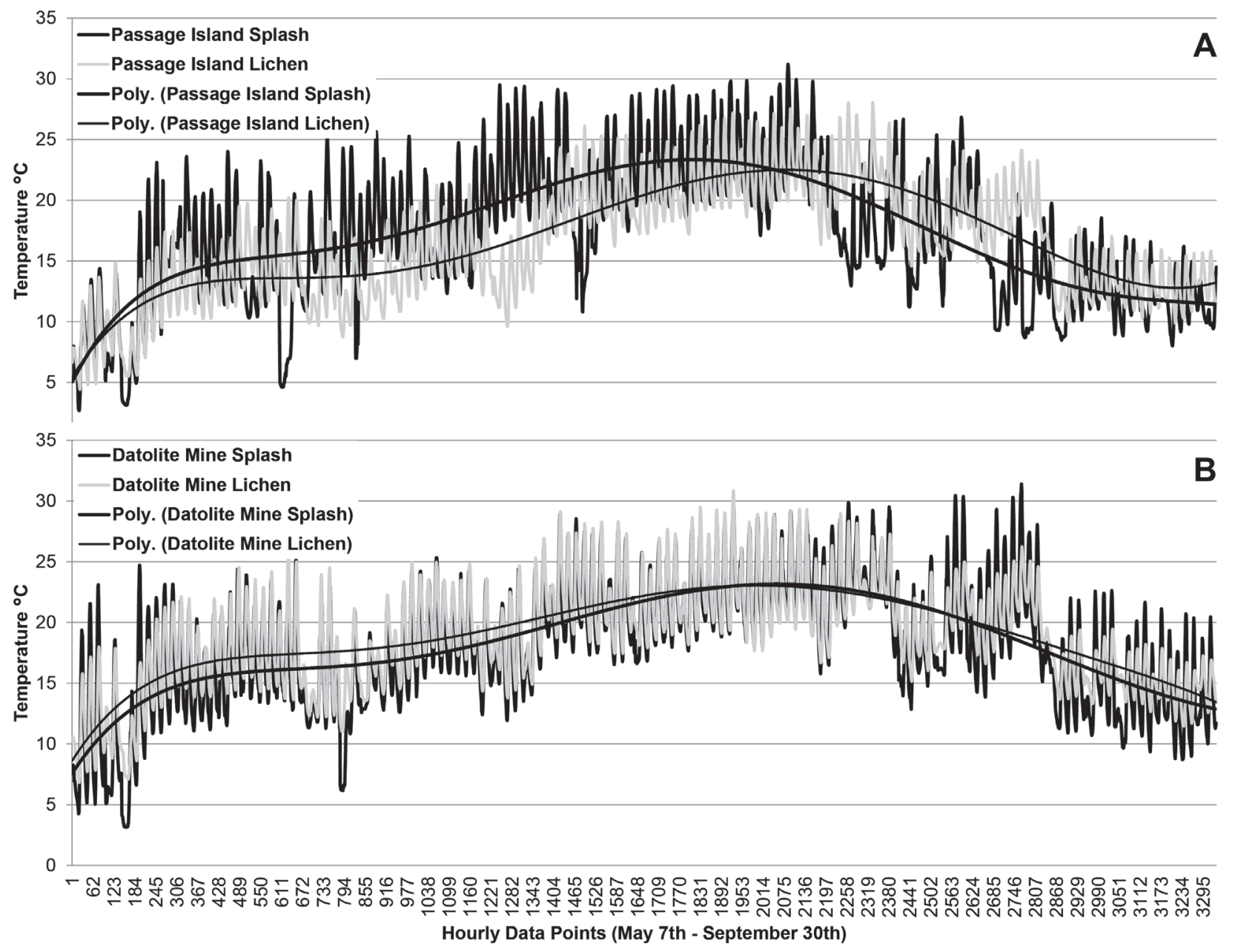

Fig. 5 Daily water temperature variation in splash (black line) and lichen (gray line) zone pools, with polynomial trend lines, at Passage Island (A) and Datolite Mine (B), Isle Royale, 2010.

could not be compared at those sites. Lichen zone pools showed a moderated daily fluctuation. Splash zone pools had an exaggerated daily fluctuation and occasional pronounced troughs due to wave inputs.

Emergence of newly detected species in each month was associated with trends in mean temperature. Two sampling dates with sharp increases in species accumulation coincided with plateaus following warming trends (Fig. 6). Malfunctioning thermistors required comparing diversity and temperature from different sites, though closely matching mean temperature trends at Passage and Datolite suggest these comparisons are appropriate. Weather patterns in the five days prior to these increases were calm with limited waves. Mean pool water temperatures began to stabilize across multiple weeks by mid-July (Fig. 7). After this point only two new species emerged in early August, and once temperature means began to significantly decline there were no new species emerging. Week 1 in early May and the cluster of weeks in September (weeks 17-20) had significantly colder pool water temperatures from adjacent time periods; late July and early August (weeks 11-13) had stable and significantly higher temperatures from all other clusters; and late spring-early summer (weeks $2-8$ ) was characterized by high variability and no distinct clustering of means (Fig. 7).

Temperature and species regressions for each zone were nearly identical, so to improve the analysis both zones were combined. While not a significant relationship ( $p=0.085, f=3.85, r^{2}=0.033$, d.f. $=1,8, \alpha=0.05$ ), there was a positive emergence response to higher temperatures (Fig. 8). Spring and fall temperature change was similar between zones, but in mid-late summer there were contradictory patterns (Table 2). There was also a onemonth shift of emergences between zones, with lichen pools having earlier emergences and an earlier plateau. 


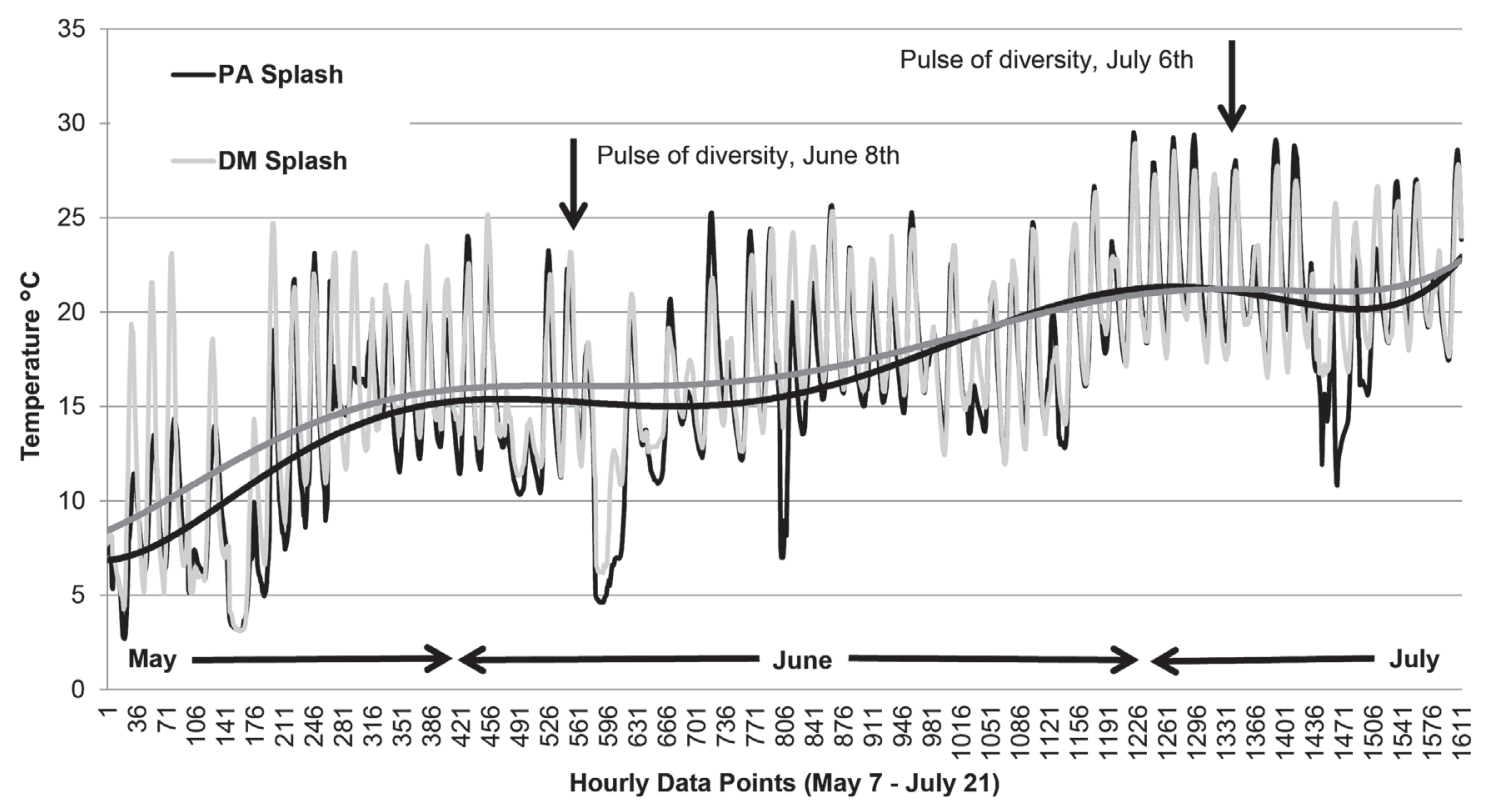

Fig. 6 Daily water temperature variation detail, and polynomial trend, in splash zone pools at Passage Island (dark lines) and Datolite Mine (gray lines), Isle Royale, 2010. Two sample dates with sharp increases of species accumulation from Raspberry Island (June 8th) and Blueberry Cove (July 6th) are noted (see text for site details).

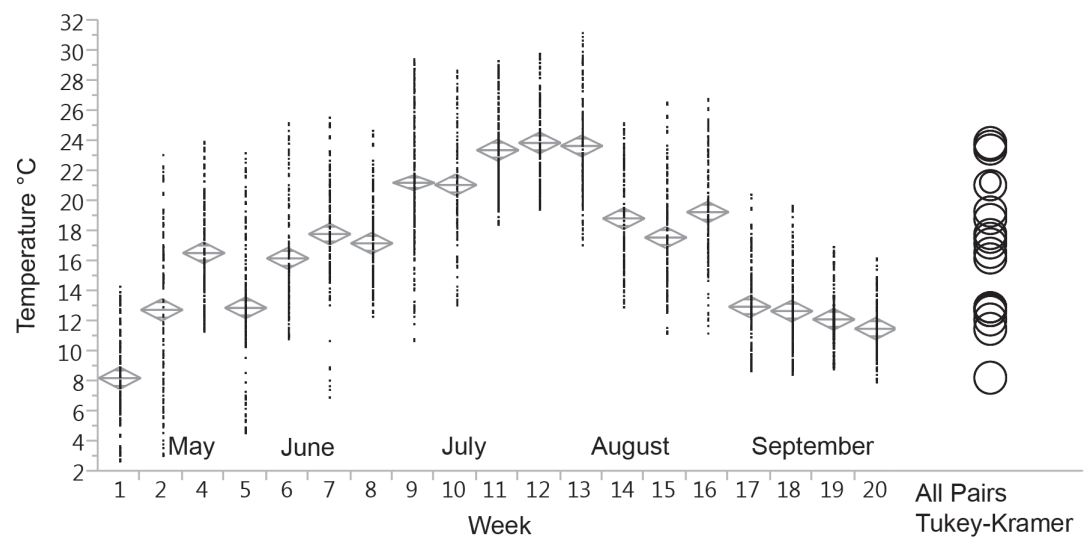

Fig. 7 Weekly water temperature means in a Passage Island splash pool, May 7 (week 1) to September 30 (week 20), 2010. Diamond center line is the mean, upper and lower points are $95 \%$ confidence intervals. Tukey-Kramer circles show significantly different means as non-intersecting or slightly intersecting circles, with nested circles not significantly different. Week 3 data were not logged by the thermistor.

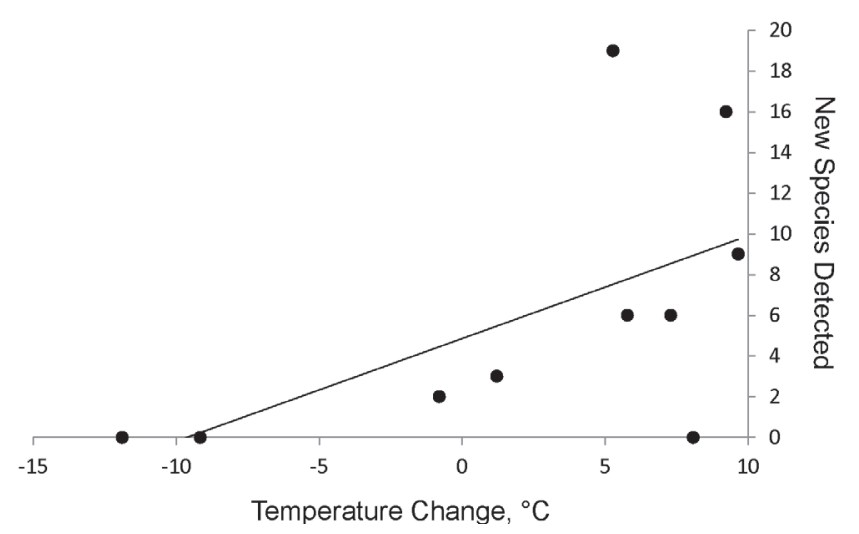

Fig. 8 Relationship between mean pool temperature change and new species detected in adjacent months. 
Table 1 Pairwise monthly comparisons of lichen zone and splash zone chironomid assemblages using Jaccard's (JCC, top number in each pair) and Whittaker's (WPS, bottom number) diversity coefficients, with both tests on a scale of 0 (completely dissimilar) to 1 (completely similar). Bold numbers indicate significant results based on N species (Real 1999) for JCC (significantly similar emerging communities identified in the lichen zone, significantly dissimilar emerging communities identified in the splash zone); ${ }^{\prime * \prime}$ indicates likely ecologically important results where WPS $\leq 0.1$.

\begin{tabular}{|c|c|c|c|c|c|c|}
\hline & & May & June & July & August & October \\
\hline \multirow{10}{*}{$\begin{array}{l}\text { Uू } \\
\text { N } \\
\text { ü } \\
\text { IU }\end{array}$} & \multirow[t]{2}{*}{ April } & 0.24 & 0.24 & 0.35 & 0.29 & 0.21 \\
\hline & & 0.48 & ${ }^{*} 0.04$ & 0.21 & 0.11 & 0.17 \\
\hline & \multirow[t]{2}{*}{ May } & & 0.50 & 0.40 & 0.56 & 0.29 \\
\hline & & & 0.16 & 0.26 & 0.21 & 0.32 \\
\hline & \multirow[t]{2}{*}{ June } & & & 0.50 & 0.57 & 0.28 \\
\hline & & & & 0.23 & 0.39 & 0.13 \\
\hline & \multirow[t]{2}{*}{ July } & & & & 0.79 & 0.41 \\
\hline & & & & & 0.61 & 0.41 \\
\hline & \multirow[t]{2}{*}{ August } & & & & & 0.41 \\
\hline & & & & & & 0.28 \\
\hline \multirow{10}{*}{ 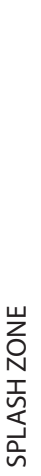 } & \multirow[t]{2}{*}{ April } & 0.22 & 0.11 & 0.13 & .16 & 0.22 \\
\hline & & 0.17 & ${ }^{*} 0.03$ & 0.11 & 0.14 & 0.20 \\
\hline & \multirow[t]{2}{*}{ May } & & 0.11 & 0.08 & 0.24 & 0.25 \\
\hline & & & ${ }^{*} 0.09$ & ${ }^{*} 0.05$ & *0.10 & ${ }^{*} 0.06$ \\
\hline & \multirow[t]{2}{*}{ June } & & & 0.44 & 0.37 & 0.11 \\
\hline & & & & 0.20 & 0.25 & ${ }^{*} 0.02$ \\
\hline & \multirow[t]{2}{*}{ July } & & & & 0.37 & 0.13 \\
\hline & & & & & 0.33 & 0.13 \\
\hline & \multirow[t]{2}{*}{ August } & & & & & 0.31 \\
\hline & & & & & & 0.20 \\
\hline
\end{tabular}

Table 2 Adjacent monthly comparisons of mean pool temperature $\left({ }^{\circ} \mathrm{C}\right)$ change and new species detected.

\begin{tabular}{lccccc}
\hline $\begin{array}{l}\text { Lichen Zone } \\
\text { Pools }\end{array}$ & $\begin{array}{c}\text { April- } \\
\text { May }\end{array}$ & $\begin{array}{c}\text { May- } \\
\text { June }\end{array}$ & $\begin{array}{c}\text { June- } \\
\text { July }\end{array}$ & $\begin{array}{c}\text { July- } \\
\text { August }\end{array}$ & $\begin{array}{c}\text { August- } \\
\text { October }\end{array}$ \\
\hline $\begin{array}{l}\text { Temperature } \\
\text { change }\end{array}$ & +9.24 & +5.79 & -0.79 & +8.09 & -9.15 \\
$\begin{array}{l}\text { New species } \\
\text { Splash Zone }\end{array}$ & 16 & 6 & 2 & 0 & 0 \\
$\begin{array}{l}\text { Pools } \\
\text { Temperature } \\
\text { change }\end{array}$ & +9.66 & +5.28 & +7.3 & +1.22 & -11.88 \\
New species & 9 & 19 & 6 & 3 & 0 \\
\hline
\end{tabular}

\section{Discussion}

\section{Monthly Emergences}

Diversity analyses show that month-by-month patterns of emergence are different by zone, with consistent chironomid species assemblages emerging throughout the ice-free season in the lichen zone and distinct seasonal transitions of species assemblages in the splash zone. Practically, this means that diversity studies on lichen zone pools can focus on months with high overall abundances and greater diversity. With a large proportion of splash-zone species emerging only in June and July, sampling could be focused on the summer assemblage, particularly since spring species were still emerging. Few species were unique to either spring or late summer. These results are similar but more robust compared to sampling from 15 Isle Royale pool sites in 2009 (Egan 2014), suggesting that zonal and seasonal emergence patterns are maintained across years.

For individual species, a seasonal pattern was often observed, where peak emergence occurred either in a single month or adjacent months. With few exceptions, even species that emerged across most or all months had a distinct peak emergence. However, assessments of voltinism are often not clear when using exuviae collections (Coffman 1973), and larvae from the same cohort may develop at variable rates (Pinder 1986). Nearly half of chironomid species in coastal pools were probably univoltine, particularly splash zone species with a narrow emergence time, with the remainder likely bivoltine.

The greatest richness of emergence was in early to mid-summer, making it a good season for detecting the most diversity and relatively high abundances. Spring and fall richness was low, representing few unique species in spring and none in fall. We expected a distinct fall emergence, or potentially a spring-fall similarity based on climatic conditions, but these did not occur. Given the detection of many cold-stenothermic species (Egan and Ferrington 2015), the limited warm season along the coast of Isle Royale, and apparently limited predation pressure in most pools (Egan et al. 2014), there is perhaps little advantage to emergence in early spring and fall when weather conditions are less predictable and food is limited. Some studies have shown that food supply can be a more important factor than abiotic conditions in regulating phenology (Armitage 1995).

Chironomid activity in pools generally appears aestival, yet climatic moderation from the lake may allow for broader seasonal activity of cold-tolerant larvae. Ice-covered shores are typical of Lake Superior in winter, with pools frozen solid for at least 3-4 months per year. Freeze tolerance is common in chironomids (Pinder 1986), and species in coastal pools must either have this ability or must recolonize pools annually, which has been shown in city fountains drained in winter (Hamerlík and Brodersen 2010). Overall, we observed a distinct seasonal transition of emergences in the splash zone, but no clear transition in the lichen zone.

\section{Temperature Patterns}

Seasonal environmental cues, such as photoperiod and temperature, are known to trigger pupation and emergence during optimal conditions (Pinder 1986; Tokeshi 1995). Significant seasonal temperature changes occurred in pools and followed a distinct seasonal pattern, with the most conspicuous changes occurring in May and September, showing transitions to and from summer conditions. Most species emerging from the 
splash zone did so only after pools significantly warmed, yet prior to stable high temperatures in late summer. This suggests that water temperature is influencing development of many splash zone occupants. In the lichen zone, however, assemblage emergences were more stable throughout the ice-free seasons. Mechanisms behind these differences may be linked to distinct nutrient conditions between zones, with mesotrophic conditions in the lichen zone and oligotrophic conditions in the splash zone (Egan et al. 2014). Differences in dissolved organic carbon have been shown to influence water temperature in small lakes (Snucins and Gunn 2000). Though pools are too shallow to stratify, dissolved carbon may help explain why splash zone pools were often warmer and had stronger diurnal temperature fluctuations than lichen zone pools, even though wave input from the cold lake was expected to keep splash pools colder.

Temperature is a key environmental factor in determining chironomid growth and development (Wiggins et al. 1980; Pinder 1986). Water warming trends allow more rapid development, along with signals to larvae that meteorological conditions are improving for emergence (Armitage 1995). This pattern has also been noted for emerging chironomids in lotic systems of Pennsylvania (Coffman 1973) and Kansas (L. C. Ferrington, unpublished data). Minimal wind and wave action in the five days prior to strong increases in splash zone emergences indicates two important points. First, in shallow pool habitats, larvae and pupae may be able to detect periods of calm winds for optimal adult swarming and egg-laying behaviors. Second, no additions of exuviae to splash zone pools via wave action occurred prior to sampling, which would have created false positive detections. This is important because littoral zone chironomids of Lake Superior in summer months are known to be active and diverse, even on exposed bedrock (Barton and Hynes 1978).

High pool temperatures were clearly related to small volumes of water heated by solar radiation in unshaded habitat. Temperature peaks of $31{ }^{\circ} \mathrm{C}$ may reach thermal maxima or influence physiological stress responses for some chironomids, though this varies by life stage (Dahlhoff et al. 2002; Eggermont and Heiri 2012). Failure of chironomid eggs to hatch is known from about $30-35^{\circ} \mathrm{C}$, and some larvae may enter diapause or aestivation during warm summer temperatures (Tokeshi 1995). Low temperatures also restrict egg hatches and larval development (Pinder 1986), which can explain why reduced emergence occurs once pool temperatures begin to significantly decline. Chironomids in cold habitats, where the breeding season is short, like Isle Royale coasts, may overwinter as prepupae, quickly emerging after a spring temperature cue (Armitage 1995). High relative abundances in April suggest this occurs for Orthocladius dubitatus, which may be multivoltine in rock pools, and species like Diamesa insignipes and Limnophyes carolinensis, which appear univoltine.

\section{Conclusions}

Future studies would benefit from a focus on collections from late spring to mid-summer when both abundance and diversity are highest, maximizing use of effort, although collecting across seasons would be important if maximizing detection of community richness and estimating phenology are goals. Chironomidae in coastal pools have variable monthly emergence patterns based on lateral shoreline zone and temperature. In addition, larvae may be able to detect and respond to calm atmospheric conditions. In general, lichen zone pools had a more stable thermal diurnal cycle, while splash zone pools had stronger daily fluctuations. However, given lack of shade, pools between zones had similar mean temperatures over time. Overall, the lichen zone assemblage and many species in the splash zone are not clearly responding to temperature, or once they start emerging the same assemblage continues to do so until mean temperatures strongly decline. In the splash zone, a distinct set of species does appear to be responding directly to trends in temperature and patterns of wind, which signal ideal conditions for emergence, swarming and egg-laying activities. In particular, a unique community component emerges only in mid-summer from splash zone pools. Local abiotic factors were found to be important in other pool systems as well, including community responses to abiotic variables such as temperature, although rock pool community dynamics are not always well-explained by standard ecological theories (Romanuk and Kolasa 2002; Vanschoenwinkel et al. 2007).

\section{Acknowledgements}

Brenda Moraska Lafrançois and Jay Glase were central to the development of this project. Comments on the draft manuscript were provided by Jacques Finlay, Ralph Holzenthal, and Roger Moon. Funding was provided to the Chironomidae Research Group by the Great Lakes Restoration Initiative, EPA Project \#90, Great Lakes Northern Forest CESU Task Agreements J6067100007 and J6067100008. Substantial logistical and technical assistance were provided by National Park Service. Laboratory procedures were supported by the Department of Entomology at the University of Minnesota and the Minnesota Agricultural Experiment Station, Project \#MIN-17-018.

\section{REFERENCES}

Armitage PD (1995) Behavior and ecology of adults. In: Armitage PD, Cranston PS, Pinder LCV (eds) The Chironomidae: Biology and ecology of non-biting midges. Chapman and Hall, London, pp. 194-219.

Austin JA, Colman SM (2007) Lake Superior summer water temperatures are increasing more rapidly than regional air temperatures: A positive ice-albedo feedback. Geophys Res Lett 34 (L06604): 1-5. 
Barton DR, Hynes HBN (1978) Wave-zone macrobenthos of the exposed Canadian shores of the St. Lawrence Great Lakes. J Gt Lakes Res 4: 27-45.

Bouchard RW, Ferrington LC Jr (2011) The effects of subsampling and sampling frequency on the use of surface-floating pupal exuviae to measure Chironomidae (Diptera) communities in wadeable temperate streams. Environ Monit Assess 181: 205-233.

Brendonck L, Jocque M, Hulsmans A, Vanshoenwinkel B (2010) Pools 'on the rocks': freshwater rock pools as a model system in ecological and evolutionary research. Limnetica 29: 25-40.

Brooks SJ, Birks HJB (2004) The dynamics of Chironomidae (Insecta: Diptera) assemblages in response to environmental change during the past 700 years on Svalbard. J Paleolimnol 31: 483-498.

Chao A, Chazdon RL, Colwell RK, Shen T-J (2005) A new statistical approach for assessing similarity of species composition with incidence and abundance data. Ecol Lett 8: 148-159.

Coffman WP (1973) Energy flow in a woodland stream ecosystem. Arch Hydrobiol 71: 281-322.

Dahlhoff EP, Stillman JH, Menge BA (2002) Physiological community ecology: variation in metabolic activity of ecologically important rocky intertidal invertebrates along environmental gradients. Integr Comp Biol 42: 862-871.

Danks HV (2007) How aquatic insects live in cold climates. Can Entomol 139: 443-471.

Day JW, Christian RR, Boesch DM, Yáñez-Arancibia A, Morris J, Twilley RR, Naylor L, Schaffner L, Stevenson C (2008) Consequences of climate change on the ecomorphology of coastal wetlands. Estuaries and Coasts 31: 477-491.

Desai AR, Austin JA, Bennington V, McKinley GA (2009) Stronger winds over a large lake in response to weakening air-to-lake temperature gradient. Nat Geosci 2: 855-858.

Egan AT (2014) Communities in freshwater coastal rock pools of Lake Superior, with a focus on Chironomidae (Diptera). $\mathrm{PhD}$ Thesis, University of Minnesota, St. Paul.

Egan AT, Lafrançois T, Edlund MB, Ferrington LC Jr, Glase J (2014) Biological studies and mapping of shoreline rock pools in three Lake Superior national parks. Natural Resource Technical Report NPS/MWRO/NRTR-2014/907. National Park Service, Fort Collins, Colorado.

Egan AT, Ferrington LC Jr (2015) Chironomidae (Diptera) in freshwater coastal rock pools at Isle Royale, Michigan. Trans Am Entomol Soc 141: 1-25.

Eggermont H, Heiri O (2012) The chironomid-temperature relationship: expression in nature and paleoenvironmental implications. Biol Rev 87: 430-456.

Ferrington LC Jr, Blackwood MA, Wright CA, Crisp NH, Kavanaugh JL, Schmidt FJ (1991) A protocol for using surface-floating pupal exuviae of Chironomidae for rapid bioassessment of changing water quality. Proc Vienna Symp, IAHS Publication 203.

Ferrington LC Jr, Coffman WP, Berg MB (2008) Chironomidae. In: Merritt RW, Cummins KW, Berg MB (eds). An introduction to the aquatic insects of North America. Kendall/Hunt Publishing Co., Dubuque, Iowa.

Hamerlík L, Brodersen KP (2010) Non-biting midges (Diptera: Chironomidae) from fountains of two European cities: micro-scale island biogeography. Aquat Insects 32: 67-79.
Hulsmans A, Vanschoenwinkel B, Pyke C, Riddoch BJ, Brendonck L (2008) Quantifying the hydroregime of a temporary pool habitat: a modeling approach for ephemeral rock pools in SE Botswana. Ecosyst 11: 89-100.

Judziewicz E (2004) Inventory and establishment of monitoring programs for special floristic elements at Isle Royale National Park, Michigan. Unpublished report to Regional Director, Midwest Region, National Park Service, Omaha, Nebraska.

Kavanaugh RG, Egan AE, Ferrington LC (2014) Factors affecting decomposition rates of chironomid (Diptera) pupal exuviae. CHIRONOMUS Newslett on Chironomidae Res 27: 16-24.

Langton PH (1991) A key to pupal exuviae of West Palearctic Chironomidae. P. H. Langton, Huntington, Cambridgeshire, England.

Legendre P, Legendre L (2012) Numerical Ecology. 3rd edition. Elsevier, Amsterdam, Netherlands.

Lurgi M, López BC, Montoya JM (2012) Novel communities from climate change. Philos Trans R Soc B 367: 2913-2922.

Mason CF (2002) Biology of freshwater pollution. 4th edition. Pearson Education Limited, Essex, England.

Pinder LCV (1986) Biology of freshwater Chironomidae. Annu Rev Entomol 31: 1-23.

Real R (1999) Tables of significant values of Jaccard's index of similarity. Misc Zool 22: 29-40.

Romanuk TN, Kolasa J (2002) Environmental variability alters the relationship between richness and variability of community abundances in aquatic rock pool microcosms. Ecoscience 9: 55-62.

Schindler DW (1997) Widespread effects of climatic warming on freshwater ecosystems in North America. Hydrol Processes 11: 1043-1067.

Snucins E, Gunn J (2000) Interannual variation in the thermal structure of clear and colored lakes. Limnol Oceanogr 45: $1639-1646$

Tokeshi M (1995) Species interactions and community structure. In: Armitage PD, Cranston PS, Pinder LCV (eds) The Chironomidae: Biology and ecology of non-biting midges. Chapman and Hall, London, pp. 297-331.

Vanschoenwinkel B, de Vries C, Seaman M, Brendonck L (2007) The role of metacommunity processes in shaping invertebrate rock pool communities along a dispersal gradient. Oikos 116: 1255-1266.

Verneaux V, Aleya L (1999) Comparison of the chironomid communities of Lake Abbaye (Jura, France) collected using five different sampling methods. Advantages of the pupal exuviae sampling. Rev des Sciences De L'eau 12: 45-63.

Wiggins GB, Mackay RJ, Smith IM (1980) Evolutionary and ecological strategies of animals in annual temporary pools. Arch Hydrobiol, Supplement 58: 97-206.

Williams DD (1996) Environmental constraints in temporary fresh waters and their consequences for the insect fauna. J N Am Benthol Soc 15: 634-650.

Wiederholm T (ed) (1986) Chironomidae of the Holarctic region. Part 2: pupae. Entomol Scand Supplement 28.

Wilson RS, Ruse LP (2005) A guide to the identification of genera of chironomid pupal exuviae occurring in Britain and Ireland. Freshwater Biological Association, Special Publication No. 13. Cumbria. 